\title{
Improving diabetes care at primary care level with a multistrategic approach: results of the DIAPREM programme
}

\author{
Mariana Prestes $^{1} \cdot$ Maria A. Gayarre $^{2}$ Jorge F. Elgart ${ }^{1} \cdot$ Lorena Gonzalez $^{1,3}$ • \\ Enzo Rucci $^{1,4} \cdot$ Jose M. Paganini $^{5} \cdot$ Juan J. Gagliardino $^{1} \cdot$ DIAPREM (DIAbetes Primary $^{1}$ \\ Care, Registry, Education and Management)
}

Received: 30 April 2017/ Accepted: 5 June 2017

(C) Springer-Verlag Italia S.r.l. 2017

\begin{abstract}
Aim To present results, 1 year postimplementation at primary care level, of an integrated diabetes care programme including systemic changes, education, registry (clinical, metabolic, and therapeutic indicators), and disease management (DIAPREM).

Methods We randomly selected and trained 15 physicians and 15 nurses from primary care units of La Matanza County (intervention-IG) and another 15 physicians/nurses to participate as controls (control-CG). Each physician-nurse team controlled and followed up 10 patients with type 2 diabetes for 1 year; both groups used structured medical records. Patients in IG had quarterly clinical appointments, whereas those in CG received traditional care. Statistical data analysis included parametric/
\end{abstract}

Managed by Massimo Porta.

Electronic supplementary material The online version of this article (doi:10.1007/s00592-017-1016-8) contains supplementary material, which is available to authorized users.

Juan J. Gagliardino

cenexaar@yahoo.com.ar

Mariana Prestes

mariianaprestes@gmail.com

Maria A. Gayarre

aylen48@yahoo.com.ar

Jorge F. Elgart

jelgart@cenexa.org

Lorena Gonzalez

lgonzalez@cenexa.org

Enzo Rucci

enzo@cenexa.org

Jose M. Paganini

paganini@netverk.com.ar nonparametric tests according to data distribution profile and Chi-squared test for proportions.

Results After 12 months, the dropout rate was significantly lower in IG than in CG. Whereas in IG HbA1c, blood pressure and lipid profile levels significantly decreased, no changes were recorded in CG. Drug prescriptions showed no significant changes in IG except a decrease in oral monotherapy.

Conclusions DIAPREM is an expedient and simple multistrategic model to implement at the primary care level in order to decrease patient dropout and improve control and treatment adherence, and quality of care of people with diabetes.

Keywords Quality of care Therapeutic education . Medical data registry - Diabetes primary care $\cdot$ Treatment adherence $\cdot$ Disease management

1 CENEXA Centro de Endocrinología Experimental y Aplicada (UNLP-CONICET), Facultad de Ciencias Médicas (UNLP), 60 y 120, 1900 La Plata, Argentina

2 Coordinadora del PRODIABA, Secretaría de Salud, Municipalidad de La Matanza, San Justo, Argentina

3 Escuela de Economía de la Salud y Administración de Organizaciones de Salud, Facultad de Ciencias Económicas (UNLP), La Plata, Argentina

4 III-LIDI, Facultad de Informática, Universidad Nacional de La Plata, La Plata, Argentina

5 INUS. Centro Interdisciplinario Universitario para la Salud, Facultad de Ciencias Médicas (UNLP), La Plata, Argentina 


\section{Introduction}

Despite available evidence supporting the concept that appropriate control of blood glucose and associated cardiovascular risk factors (CVRFs) can reduce diabetes complications-the major cause of morbidity, mortality, and costs of the disease [1-7] - these preventive strategies have not been widely incorporated into clinical practice [8]. Consequently, care received by people with diabetes is frequently far from optimal [9-15].

Several factors contribute to this disappointing situation such as a) inadequate knowledge and experience of healthcare providers [12], b) inadequate provider attitude towards application of guidelines [16, 17], c) limited patient access to care, d) poor adherence with self-care and treatment, and e) scant attention given patient education $[8,17]$. Lack of continuous evaluation and systematic registry of medical outcomes with concomitant treatment adjustments close the vicious circle that leads to poor care outcomes [9, 11, 18]. Therefore, inappropriate control/ treatment is the final common path leading to the high morbimortality of the disease.

Effective models of diabetes care which include systemic changes and patient and/or physician education help to overcome most of the above-mentioned problems. Systemic changes most widely implemented included provision of specific care guidelines and reminders, improved access to care by reduction in financial/administrative barriers to care, and patient/provider feedback to monitor care outcomes. Indeed, a review of educational interventions in disease management programmes of chronic diseases, including diabetes, concluded that most programmes directed at providers and patients improved care outcomes [19]).

In Argentina, there are three health sectors (public health, social security, and private). The social security and private sectors cover around 48 and $10 \%$ of the population, respectively, and the extent of health coverage is determined by law in the Mandatory Medical Program (PMO). The public health sector provides universal access to free health care to almost half of the population (mostly unemployed and low-income population not insured by social security or private sector) through primary care units (PCU) and public hospitals. PCUs include different types of disease management programmes for ambulatory treatment of chronic diseases such as diabetes, providing a free supply of drugs such as human insulin, some oral drugs, and a limited number of strips to self-monitor blood glucose (SMBG).

We attempted to improve quality of diabetes care at the primary care level and consequently improve treatment outcomes by implementing at that level of the public health sector, an integrated diabetes care programme that includes systemic changes, education, registry (clinical, metabolic, and therapeutic indicators), education (physicians and nurses), and disease management (DIAPREM: DIA betes Primary care, Registry, Education and Management) [20]. Here, we describe the clinical and metabolic outcomes after a 1-year follow-up of patients in the intervention group, comparing them to those who received customary care.

\section{Methods}

\section{Study design}

Detailed description of the DIAPREM strategy has been already reported [20]. Consequently, we now briefly describe its background and contents.

Argentina has 40,117,096 inhabitants (2010 National Census), and $39 \%$ of them live in the province of Buenos Aires, of whom 1,775,816 (11\%) live in La Matanza County. According to the prevalence defined by the 2009 National Risk Factors Survey [21], our diabetes population is around 2,892,000 people; only about half of them know they have the disease $(1,445,973) ; 70 \%$ of those diagnosed are in regular treatment $(1,012,181)$. Half of this population receives free care from the public health system $(506,091$ people). Of this diabetes population, $4.43 \%$ lives in one area (La Matanza) of the city suburbs in the province of Buenos Aires, a low-income population with $34 \%$ has unsatisfied basic needs, and only $40 \%$ of people have completed their primary education.

Figure 1 shows the DIAPREM design. Of the 40 primary care units (PCU) of La Matanza Health Secretariat, we randomly selected 30 physicians and 30 nurses. Of those, 15 were randomly selected to be trained (IG group), and another group of 15 physicians and nurses from another 15 PCUs were also randomly selected and used as controls (CG group).

Rather than using restrictive patient selection criteria, our criterion was for the patient sample to represent common daily practice in the study area. For this purpose, each physician-nurse team took care of and followed up 10 patients: adults of both genders with type 2 diabetes (T2D) for 1 year; each patient was required to attend clinical appointments at least every 3 months (150 people with T2D in the CG and 150 people in the IG). People with expected short survival (cancer or terminal conditions), different types of addictions or psychiatric disorders, were excluded from the selection.

During the recruitment phase, we had several meetings with local coordinators and authorities from participating organizations to explain the rationale, importance, aims, 
Fig. 1 Study design *PHCP received e-learning courses. $\dagger$ Nurses received face-to-face courses

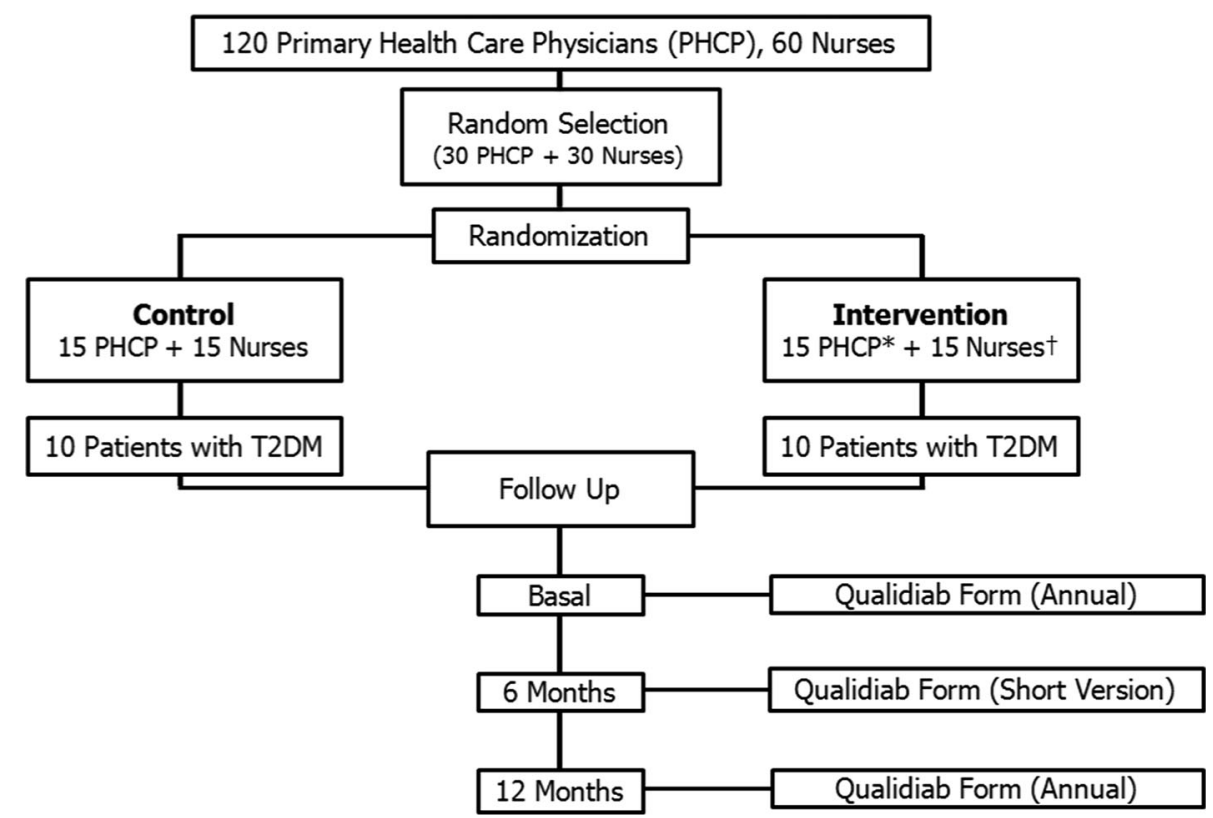

activities, timetable, and methodology selected for the study.

\section{Main outcomes}

Changes in HbA1C from baseline to the end of the study were considered the primary outcome variable. Other relevant outcomes were considered secondary: the proportion of patients that attained goals such as $\mathrm{HbA} 1 \mathrm{c}<7.0 \%$, glycaemia $<100 \mathrm{mg} / \mathrm{dL}$, blood pressure $<130 / 80 \mathrm{mmHg}$, cholesterol $<200 \mathrm{mg} / \mathrm{dL}$, and triglycerides $<150 \mathrm{mg} / \mathrm{dL}$.

\section{Statistical power and sample size}

Considering $1.7 \%$ the standard deviation of change in $\mathrm{HbA} 1 \mathrm{c}$, with a $5 \%$ level of significance and $80 \%$ power, we needed 93 patients in each group to detect a decrease of $0.5 \%$ in the main outcome. Thereafter, we chose to increase the sample size by $50 \%$ at the first stage, assuming this would be the rate of dropout or failure to follow-up. This totalled 140 patients for each group. Finally, for that purpose, we decided to recruit at least 10 patients per physician-nurse pair.

Consequently, the programme started with a sample size of 157 patients for CG and 154 for the IG.

\section{Interventions}

Diabetes training course for physicians Physicians in the IG attended an online course with 14 compulsory and 12 optional modules, plus $8 \mathrm{~h}$ of practical activities completed at a national reference centre. This course was released through the School of Medicine of the National University of La Plata (Argentina) and Indiana University (USA).

Each participant also received a manual with all the algorithms for diagnosis, control, and treatment of T2D included in the modules [22]. Physicians in the CG did not receive this training.

Nurse education Nurses in the IG attended in person a 5-day full-time intensive theoretical and practical course given at the Bernardo A. Houssay Center (La Plata, Argentina) which also included practical activities in the teaching hospital of the School of Medicine of the National University of La Plata.

Patient follow-up and call centre activities Participants in the IG were seen every three months in a programmed visit; to decrease dropouts, the call centre called them by telephone to remind them of their next appointment. Also, once a year, the call centre gave each patient an appointment for cardiovascular and ophthalmological controls done at the hospital at the same morning. In this way, we tried to facilitate attendance to these controls and minimize the number of work days missed.

\section{Data registry}

We used a structured registry form developed and validated by our group (QUALIDIAB) [10] to collect patients' clinical, biochemical, educational, and therapeutic data previous to and after 6 and 12 months of the DIAPREM implementation. QUALIDIAB registry includes clinical, metabolic, and associated CVRF indicators, degree of diabetes education, hospitalization events, and type of treatment prescriptions. These forms were filled in by the 
physicians and nurses in both groups who were trained previously to record data properly on the data registry. The QUALIDIAB system also includes a feedback mechanism: physicians and nurses received a form from each patient comparing treatment target values and current values of different clinical and metabolic indicators ( $\mathrm{HbAlc}$ and the other CVRF); if the patient did not achieve target values, the form suggests the issues the care team should focus on in particular. In this study, feedbacks were not available to the $\mathrm{CG}$

\section{Data analysis}

We used the Statistical Package for Social Sciences version 15 (SPSS Inc, Chicago, IL, USA). Descriptive statistics are presented as percentages and mean \pm standard deviation (SD). Group comparisons for continuous variables were made by a parametric or nonparametric test depending on the data distribution profile. The Chi-squared test was used to estimate differences between proportions. Significance was established at $p \leq 0.05$.

\section{Ethical issues}

The study protocol was analysed and approved by the Bioethical Committee of the National University of La Plata. The study was developed according to the Good Practice Recommendations (International Harmonisation Conference) and the ethical guidelines of the Helsinki Declaration. All subjects gave their written informed consent to participate in the study, and it was signed before their inclusion in the study cohort. At the end of the study, the 15 physicians and 15 nurses who were initially in the control group will receive the same training courses received previously by the intervention group.

\section{Results}

\section{Dropouts}

During the 1-year follow-up, patients who dropped out were significantly fewer in the intervention than in the control group (28 and 48\%, respectively; $p<0.0003$ ). No significant differences were found between clinical and metabolic characteristics of adherent compared to dropout patients in any of the groups (data not shown).

\section{Clinical and metabolic parameters}

Patients in the CG showed no significant improvement of their clinical and metabolic indicators during the 1-year follow-up, except a nonsignificant decrease in total cholesterol at 12 months and a transitory decrease in LDLc levels at 6 months (Table 1). Conversely, in the IG, diastolic blood pressure, HbAlc, and all lipid fractions decreased significantly at 6 months with either sustained or further improvement at 12 months (Table 1). This group also showed a small but nonsignificant decrease in BMI values.

The magnitude of the significant decreases in DBP, glycaemia, HbAlc, total and LDL-cholesterol, and TG levels attained values of $-4.6 \mathrm{mmHg},-17.9 \mathrm{mg} / \mathrm{dL}(-0.99 \mathrm{mmol} /$ L), $\quad-14.9 \mathrm{mg} / \mathrm{dL} \quad(-0.39 \mathrm{mmol} / \mathrm{L}), \quad-9.2 \mathrm{mg} / \mathrm{dL} \quad(-0.24$ $\mathrm{mmol} / \mathrm{L})$, and $-25.7 \mathrm{mg} / \mathrm{dL}(-0.29 \mathrm{mmol} / \mathrm{L})$, respectively.

Both groups showed a significant increase in the percentage of people at the goal for systolic blood pressure and total cholesterol, but this increase was larger in the IG (Table 2).

\section{Pattern of drug prescriptions}

The above-mentioned improvement was not associated with significant changes in drug treatment of hyperglycaemia, blood pressure, and dyslipidemia, except a significant decrease in monotherapy with oral antidiabetic agents (Table 3).

A comparable percentage of people with dyslipidemia or hypertension was in treatment in the CG at either the basal or 12-month control (Table 4). A similar prescriptive situation was observed in people with hypertension in the IG. Conversely, at the 12-month control, the percentage of treated patients with dyslipidemia increased significantly in the latter group. This value was significantly higher than the percentage in the CG.

\section{Annual eye and cardiovascular evaluation}

Control of micro- and macroangiopathic impact of diabetes improved significantly in the intervention group (around $100 \%$ ) compared with the control group (75\%) (Table 5).

\section{Discussion}

In our previous report on DIAPREM, we demonstrated that care provided to our population with $\mathrm{T} 2 \mathrm{D}$ and associated CVRF at the primary care level was not effective enough to prevent development and progression of chronic complications of the disease [20]. This concept was based on $\mathrm{HbA1c}$ levels and other indicators of clinical and metabolic control, also the annual frequency of chronic complication evaluation, and the absence of systematic clinical records as well as inadequate drug prescription. We assumed that unfortunately, this poor provision of care was a common picture all around the world rather than an isolated problem 
Table 1 Clinical and metabolic outcomes

\begin{tabular}{|c|c|c|c|c|c|}
\hline \multirow[t]{2}{*}{ Parameters } & \multicolumn{3}{|l|}{ Results } & \multicolumn{2}{|c|}{$p$ value } \\
\hline & Basal & After 6 months & After 12 months & A & $\mathrm{B}$ \\
\hline \multicolumn{6}{|l|}{ Control group } \\
\hline Male & $32 \%(81)$ & & & - & \\
\hline Age (years) & $55.2 \pm 9.91(81)$ & & & & \\
\hline BMI $\left(\mathrm{kg} / \mathrm{m}^{2}\right)$ & $34.9 \pm 11.5(77)$ & $33.4 \pm 8.3(74)$ & $34 \pm 7(80)$ & 0.31 & 0.60 \\
\hline SBP (mmHg) & $129.9 \pm 17.6(81)$ & $130.8 \pm 17.7(80)$ & $126.8 \pm 15.1(81)$ & 0.68 & 0.06 \\
\hline DBP (mmHg) & $79.9 \pm 10.6(81)$ & $79.3 \pm 10.3(80)$ & $78.2 \pm 9.5(81)$ & 0.48 & 0.20 \\
\hline Glycaemia (mg/dL) & $153.4 \pm 58.5(80)$ & $156.1 \pm 61.4(81)$ & $146.3 \pm 46.5(81)$ & 0.6 & 0.33 \\
\hline HbA1C (\%) & $7.76 \pm 2(81)$ & $7.66 \pm 1.7(81)$ & $7.5 \pm 1.2(81)$ & 0.6 & 0.24 \\
\hline$(\mathrm{mmol} / \mathrm{mol})$ & $61 \pm 21.9$ & $60 \pm 18.6$ & $58 \pm 13.1$ & & \\
\hline Creatinine (mg/dL) & $1.2 \pm 1.7(67)$ & $0.9 \pm 1(63)$ & $1.1 \pm 1.3(72)$ & 0.65 & 0.32 \\
\hline Proteinuria (mg/dL) & $2.8 \pm 6.7(21)$ & $0.6 \pm 0.8$ & $0.35 \pm 0.3(11)$ & 0.12 & 0.57 \\
\hline Total cholesterol (mg/dL) & $194.7 \pm 43.9(78)$ & $188.5 \pm 48.4(80)$ & $185 \pm 42(80)$ & 0.28 & 0.058 \\
\hline HDL-c (mg/dL) & $48.1 \pm 15.9(71)$ & $48.5 \pm 10.5(72)$ & $47.1 \pm 18.3(72)$ & 0.95 & 0.67 \\
\hline LDL-c (mg/dL) & $118.1 \pm 39.1(70)$ & $108.5 \pm 33.7(74)$ & $119 \pm 36.1(72)$ & 0.01 & 0.98 \\
\hline Triglyceride (mg/dL) & $160 \pm 77.4(78)$ & $166.2 \pm 88.6(74)$ & $149.7 \pm 79.6(76)$ & 0.38 & 0.38 \\
\hline \multicolumn{6}{|l|}{ Intervention group } \\
\hline Male & $35 \%(111)$ & & & - & - \\
\hline Age (years) & $55.2 \pm 9.2(111)$ & & & & \\
\hline BMI (kg/m2) & $33.1 \pm 6.8(108)$ & $32.9 \pm 6.6(108)$ & $32.3 \pm 6.8(110)$ & & \\
\hline SBP (mmHg) & $126.4 \pm 15.8(111)$ & $126.6 \pm 13.4(111)$ & $124.7 \pm 11.6(110)$ & 0.90 & 0.22 \\
\hline DBP (mmHg) & $80.7 \pm 10.8(111)$ & $77.5 \pm 9.7(111)$ & $77.8 \pm 9.4(110)$ & 0.001 & 0.006 \\
\hline Glycaemia (mg/dL) & $161 \pm 70(111)$ & $150 \pm 53(110)$ & $143.1 \pm 51(111)$ & 0.03 & 0.02 \\
\hline $\operatorname{HbA1C}(\%)$ & $7.652 .1(111)$ & $7.22 \pm 1.6(111)$ & $7.18 \pm 1.4(111)$ & 0.01 & 0.004 \\
\hline$(\mathrm{mmol} / \mathrm{mol})$ & $60 \pm 23$ & $55 \pm 17.5$ & $55 \pm 15.3$ & & \\
\hline Creatinine (mg/dL) & $1.6 \pm 2.3(100)$ & $1.29 \pm 1.8(99)$ & $1.9 \pm 2.5(108)$ & 0.20 & 0.30 \\
\hline Proteinuria $(\mathrm{mg} / \mathrm{dL})$ & $0.8 \pm 3(47)$ & $0.5 \pm 1(42)$ & $0.7 \pm 1.4(54)$ & 0.92 & 0.80 \\
\hline Total cholesterol (mg/dL) & $196.9 \pm 46.3(108)$ & $184.5 \pm 34.2(110)$ & $182 \pm 36(111)$ & 0.002 & 0.001 \\
\hline HDL-c (mg/dL) & $49.1 \pm 21.9$ & $45 \pm 10(107)$ & $45.3 \pm 9.7(110)$ & 0.04 & 0.07 \\
\hline LDL-c (mg/dL) & $117 \pm 38.1(104)$ & $105.929 .3(106)$ & $107.8 \pm 30.9(110)$ & 0.01 & 0.05 \\
\hline Triglyceride (mg/dL) & $201.2 \pm 141(105)$ & $181 \pm 105$ (109) & $175.5 \pm 99(111)$ & 0.03 & 0.05 \\
\hline
\end{tabular}

Values are mean \pm standard deviation (SD). Number of cases in parentheses. $B M I$ body mass index, $S B P$ systolic blood pressure $D B P$ diastolic blood pressure, $F B G$ fasting blood glucose, $e G F R$ estimated glomerular filtration rate, $H D L-c$ HDL-cholesterol, $L D L-c$ LDL-cholesterol. $p$ values represent: $A$, basal versus 6 months; $B$, basal versus 12 months

occurring at the primary care level of a developing country. Supporting this concept, two recent reviews analysed the situation of attainment of treatment targets in people with T2D and concluded that a large proportion of them failed to reach glycaemic targets due to a combination of factors, mainly poor adherence to treatment prescription and clinical/prescription inertia from healthcare team members $[23,24]$. Further, Blondel et al. mentioned that this condition that favours the development and progression of chronic complications results from impaired attitudes, perceptions, and behaviours of healthcare providers, in particular frequent delays in the prescription of appropriate interventions to achieve glycaemic targets. These authors concluded that a better understanding of these factors would facilitate implementation of suitable strategies to assist healthcare team members to prescribe more timely treatment to control blood glucose level.

On account of the above-mentioned evidences of worldwide and local poor quality of care provided to people with T2D, we call for urgent implementation of effective care strategies to overcome these problems; simultaneously, we have also decided to initiate this implementation at the primary care level and with general practitioners (GPs) and nurses, since they represent the first 
Table 2 Percentage of people who achieved treatment target values of clinical and metabolic parameters

\begin{tabular}{|c|c|c|c|c|c|c|c|}
\hline \multirow[t]{2}{*}{ Parameters } & \multicolumn{3}{|l|}{ Control } & \multicolumn{3}{|c|}{ Intervention } & \multirow[t]{2}{*}{$p \dagger$} \\
\hline & Basal (\%) & 12 months $(\%)$ & $p^{*}$ & Basal (\%) & 12 months $(\%)$ & $p^{*}$ & \\
\hline $\mathrm{SBP}<130 \mathrm{mmHg}$ & 46 & 68 & 0.04 & 52 & 84 & 0.00 & 0.009 \\
\hline $\mathrm{DBP}<80 \mathrm{mmHg}$ & 72 & 74 & 0.72 & 68 & 77 & 0.1 & 0.69 \\
\hline $\mathrm{BP}<130 / 80 \mathrm{mmHg}$ & 55 & 59 & 0.63 & 62 & 73 & 0.08 & 0.04 \\
\hline Glycaemia $<100 \mathrm{mg} / \mathrm{dL}$ & 16 & 14 & 0.63 & 19 & 10 & 0.056 & 0.43 \\
\hline $\mathrm{HbA} 1 \mathrm{c}<7 \%$ & 41 & 36 & 0.517 & 45 & 57 & 0.08 & 0.004 \\
\hline Cholesterol $<200 \mathrm{mg} / \mathrm{dL}$ & 51 & 69 & 0.024 & 57 & 76 & 0.004 & 0.31 \\
\hline Triglyceride $<150 \mathrm{mg} / \mathrm{dL}$ & 51 & 63 & 0.13 & 44 & 55 & 0.1 & 0.26 \\
\hline
\end{tabular}

$S B P$ systolic blood pressure, $D B P$ diastolic blood pressure, $B P$ blood pressure, * Basal versus 12 months (Chi-squared test). $\dagger$ Chi-squared test (control vs. intervention at 12 months)

Table 3 Type of treatment

\begin{tabular}{|c|c|c|c|c|c|c|c|}
\hline \multirow[t]{2}{*}{ Treatment } & \multicolumn{3}{|l|}{ Control } & \multicolumn{3}{|l|}{ Intervention } & \multirow[t]{2}{*}{$p \dagger$} \\
\hline & Basal n (\%) & 12 months $\mathrm{n}(\%)$ & $p^{*}$ & Basal n (\%) & 12 months $\mathrm{n}(\%)$ & $p^{*}$ & \\
\hline \multicolumn{8}{|l|}{ Hyperglycaemia } \\
\hline Only LSC & $1(1)$ & - & & - & - & & \\
\hline Treated with insulin or OAD & $80(99)$ & $81(100)$ & - & $111(100)$ & $111(100)$ & - & - \\
\hline Monotherapy & $24(30)$ & $21(26)$ & 0.11 & $49(44)$ & $41(37)$ & 0.047 & 0.10 \\
\hline Combined OAD ( 2 or more) & $21(26)$ & $21(26)$ & 0.75 & $31(28)$ & $31(28)$ & 0.79 & 0.75 \\
\hline Insulin + OAD ( 1 or more $)$ & $27(33)$ & $29(36)$ & 0.37 & $24(22)$ & $33(30)$ & 0.09 & 0.34 \\
\hline Insulin & $9(11)$ & $10(12)$ & 0.08 & $7(6)$ & $6(5)$ & 0.22 & 0.08 \\
\hline \multicolumn{8}{|l|}{ Hypertension } \\
\hline Only LSC & $5(7)$ & $6(8)$ & 0.78 & $5(5)$ & $2(2)$ & 0.4 & 0.10 \\
\hline Treated with antihihypertensive & $67(93)$ & $68(92)$ & - & $91(95)$ & $99(98)$ & - & - \\
\hline Monotherapy & $29(43)$ & $30(44)$ & 0.93 & $47(52)$ & $42(43)$ & 0.29 & 0.86 \\
\hline 2 antihihypertensives & $27(40)$ & $27(40)$ & 0.76 & $27(29)$ & $37(37)$ & 0.12 & 0.71 \\
\hline 3 or more & $11(17)$ & $11(16)$ & 0.51 & 17 (19) & $20(20)$ & 0.71 & 0.50 \\
\hline \multicolumn{8}{|l|}{ Dyslipidemia } \\
\hline Only LSC & $28(47)$ & $18(33)$ & 0.14 & $30(36)$ & $16(17)$ & 0.004 & 0.02 \\
\hline Treated with statins & $32(53)$ & $36(67)$ & - & $53(64)$ & $76(83)$ & - & - \\
\hline Monotherapy & $30(94)$ & $30(83)$ & 0.95 & $51(96)$ & $63(83)$ & 0.99 & 0.97 \\
\hline 2 statins & $2(6)$ & $6(17)$ & 0.95 & $2(4)$ & $13(17)$ & 0.99 & 0.97 \\
\hline
\end{tabular}

Proportions of cases in parentheses. $L S C$ lifestyle changes, OAD oral antidiabetic drug. * Basal versus 12 months (Chi-squared test). $\dagger$ Chisquared test (control vs. intervention at 12 months)

scenario that receives people with diabetes and CVRF who request disease management [25]. Outcomes of the 1-year DIAPREM implementation showed that, in the intervention group, we significantly improved faulty diabetes care processes and reversed undesirable care outcomes.

In the intervention group, the dropout rate decreased significantly to almost half the rate recorded in the control group and at the same time also significantly increased the ophthalmological and cardiovascular annual controls. These changes were associated with significant and sustained improvement in $\mathrm{HbA1c}$, blood pressure values, and serum lipid profile without marked changes in drug prescriptions. Since we have applied a "multistrategic approach to improve quality of care", all these changes could be ascribed to different factors which we will try to disaggregate in order to provide a reasoned explanation.

One of these factors might be the inclusion of the call centre to remind patients of their programmed control visits; others might be the systematic record of clinical, 
Table 4 Frequency of hypertension and dyslipidemia treatment

\begin{tabular}{|c|c|c|c|c|c|c|c|}
\hline \multirow[t]{2}{*}{ Treatment } & \multicolumn{3}{|l|}{ Control } & \multicolumn{3}{|l|}{ Intervention } & \multirow[t]{2}{*}{$p^{\dagger}$} \\
\hline & Basal \% (n) & 12 months $\%(\mathrm{n})$ & $p^{*}$ & Basal \% (n) & Annual \% (n) & $p^{*}$ & \\
\hline \multicolumn{8}{|l|}{ Dyslipidemia } \\
\hline No treated & $51(33)$ & $52(31)$ & & $46(42)$ & $26(26)$ & & \\
\hline Treated & $49(31)$ & 48 (29) & 0.99 & $54(49)$ & $74(75)$ & 0.012 & 0.01 \\
\hline On target & $13(4)$ & $21(6)$ & & $12(6)$ & $23(17)$ & & \\
\hline Under target & 87 (27) & $79(23)$ & 0.79 & $88(43)$ & $77(58)$ & 0.16 & 0.94 \\
\hline \multicolumn{8}{|l|}{ Hypertension } \\
\hline No treated & $7(5)$ & $8(6)$ & & $5(5)$ & $3(3)$ & & \\
\hline Treated & $93(67)$ & $92(68)$ & 0.76 & $95(91)$ & 97 (98) & 0.63 & 0.36 \\
\hline Target & $39(26)$ & $44(30)$ & & $38(35)$ & $47(46)$ & & \\
\hline Under target & $61(41)$ & $56(38)$ & 0.60 & $62(56)$ & $53(52)$ & 0.36 & 0.89 \\
\hline
\end{tabular}

Number of cases in parentheses. * Basal versus 12 months (Chi-squared test). $†$ Chi-squared test (control vs. intervention at 12 months)

\begin{tabular}{|c|c|c|c|c|c|c|c|}
\hline \multirow[t]{2}{*}{ Parameter } & \multicolumn{3}{|l|}{ Control } & \multicolumn{3}{|l|}{ Intervention } & \multirow[t]{2}{*}{$p \dagger$} \\
\hline & Basal & 12 months & $p^{*}$ & Basal & 12 months & $p^{*}$ & \\
\hline Eye test & $63.8 \%(72)$ & $75.3(77)$ & 0.128 & $48(\%)(102)$ & $100(\%)(105)$ & 0.000 & 0.000 \\
\hline $\mathrm{CV}$ evaluation & $49.3 \%(77)$ & $68.9(77)$ & 0.013 & $59.5(\%)(97)$ & $98.1(\%)(105)$ & 0.000 & 0.000 \\
\hline
\end{tabular}

Number of cases in parentheses. $C V$ cardiovascular. * Basal versus 12 months (Chi-squared test). $\dagger$ Chisquared test (control vs. intervention at 12 months)
Table 5 Frequency of annual micro- and macroagiopaties performance support our previous positive experience with its implementation [30, 31].

Our multistrategic approach has facilitated access to regular $\mathrm{HbA} 1 \mathrm{c}$ measurement, and this initiative has been shown to improve diabetes management at the primary care level in developing countries such as South Africa [32]. Similar success was reported in remote Australian indigenous communities [33].

Finally, our approach to care of people with T2D and CVRF also included some aspects of the care providing process not frequently considered an important conditioner of its quality, particularly at the primary care level. This specific point is based on the assumption that achieved outcome depends on medical technology but also on whether what is currently known as "good" medical care has been properly applied. We have also considered the structure, administrative, and related processes that support care provision, availability, and adequacy of facilities and equipment; the qualifications of medical staff and their organization as well as the administrative structure and programme operation of our primary care units. A detailed description of all these aspects and their impact on care quality was already published in 2005 by Donabedian [34].

In order to test whether the significant clinical and metabolic changes recorded in the Intervention Group could have clinical significance, we have compared the 
magnitude of such changes with data reported in the literature. For that purpose, we took advantage of the systematic review and meta-analysis reported by Tricco et al. [35] on the effectiveness of quality improvement (QI) strategies on diabetes care, particularly assessing its impact on glycated haemoglobin (HbAlc), and other cardiovascular risk factors indicators. The result of such comparison showed that except for the changes observed in SBP, every outcome recorded in DIAPREM was larger than those reported in the literature for the 12-month follow-up period. It must be stresses that none of our baseline data was as high as those considered by Tricco et al., to render larger outcomes differences.

In brief, implementation of our multistrategic diabetes care programme-a combination of systemic changes, education, consistent patient registry, and disease management-has significantly improved patient' adherence, quality of care, and treatment adherence; these changes were associated with high motivation of the healthcare team participating members, as well as the support of local health authorities. Even though we did not quantify healthcare team members motivation, they continuously manifested such attitude through permanent expressions of their satisfaction with their participation in the DIAPREM programme. All together, they have led to significant improvement in clinical and metabolic care indicators and optimization of human and economic resources regularly available at the primary care level. These simple and low-cost interventions yielded appreciable improvement in diabetes and associated CVRF control. Consequently, healthcare authorities must be aware of these results and endeavour to replicate the model in countries/regions with restricted health budgets in order to alleviate the heavy burden that T2D imposes on the public health budget, the community and, most of all, on the people suffering from this disease.

Acknowledgements DIAPREM implementation was partially supported by a grant provided by the World Diabetes Foundation (WDF12-761). The authors heartily acknowledge the generous cooperation of the La Matanza County health authorities as well as that of the Ministry of Health of the Province of Buenos Aires. The authors also thank Biochem. Cinthia Gonzales, Coordinator of the Municipal Laboratory Network, Ophthalmologist Marcelo Diaz, and administrative staffers Susana Lopez and Gladys Morello for their efficient support. MP is a research fellow of the Comision de Investigaciones Cientificas de la Provincia de Buenos Aires CIC/PBAUNLP; LG is a UNLP fellow, ER is a CONICET research fellow, and JFE and JJG are CONICET career researchers.

\section{Compliance with ethical standards}

Conflict of interest The authors declare that they have no competing interests.

Human and animal rights disclosure All procedures in studies involving human participants were performed according to the ethical standards of the institutional and/or national research committee and the 1964 Helsinki Declaration and its later amendments or comparable ethical standards. The study protocol was analysed and approved by the Bioethical Committee of the National University of La Plata.

Informed consent Informed consent was given in writing by all individual subjects included in the study.

\section{References}

1. Williams R, Van Gaal L, Lucioni C, CODE-2 Advisory Board (2002) Assessing the impact of complications on the costs of Type II diabetes. Diabetologia 45(7):S13-S17. doi:10.1007/ s00125-002-0859-9

2. UK Prospective Diabetes Study Group (1998) Intensive bloodglucose control with sulphonylureas or insulin compared with conventional treatment and risk of complications in patients with type 2 diabetes (UKPDS 33). Lancet 352:837-853. doi:10.1016/ S0140-6736(98)07019-6

3. UK Prospective Diabetes Study Group (1998) Tight blood pressure control and risk of macrovascular and microvascular complications in type 2 diabetes: UKPDS 38. BMJ 317:703-713. doi:10.1136/bmj.317.7160.703

4. Gaede P, Vedel P, Larsen N, Jensen GV, Parving HH, Pedersen O (2003) Multifactorial intervention and cardiovascular disease in patients with type 2 diabetes. N Engl J Med 348:383-393. doi:10. 1056/NEJMoa021778

5. Gray M, Raikou A McGuire, United Kingdom Prospective Diabetes Study (UKPDS) Group et al (2000) Cost effectiveness of an intensive blood glucose control policy in patients with type 2 diabetes: economic analysis alongside randomized controlled trial (UKPDS 41). BMJ 320:1373-1378

6. Gray Clarke P, Farmer A, Holman R, United Kingdom Prospective Diabetes Study (UKPDS) Group (2002) Implementing intensive control of blood glucose concentration and blood pressure in type 2 diabetes in England: cost analysis (UKPDS 63). BMJ 325:860. doi:10.1136/bmj.325.7369.860

7. Klonoff DC, Schwartz DM (2000) An economic analysis of interventions for diabetes. Diabet Care 23:390-404. doi:10.2337/dc08-S95

8. Karter AJ, Stevens MR, Herman WH, Translating Research Into Action for Diabetes Study Group et al (2003) Out-of-pocket costs and diabetes preventive services: the Translating Research Into Action for Diabetes (TRIAD) study. Diabet Care 26(8):2294-2299. doi:10.2337/diacare.26.8.2294

9. Beckles GL, Engelgau MM, Narayan KM, Herman WH, Aubert RE, Williamson DF (1998) Population-based assessment of the level of care among adults with diabetes in the U.S. Diabet Care 21:1432-1438. doi:10.2337/diacare.21.9.1432

10. Gagliardino JJ, de la Hera M, Siri F, Grupo de Investigacion de la Red Qualidiab (2001) Evaluación de la calidad de la asistencia al paciente diabético en America Latina. RevPanam Salud Publica/ Pan Am J PublicHealth 10:309-317

11. Saaddine JB, Engelgau MM, Beckles GL, Greg EW, Thompson TJ, Narayan KM (2002) A diabetes report card for the United States: quality of care in the 1990s. Ann Intern Med 136:565-574. doi:10.7326/0003-4819-136-8-200204160-00005

12. Renders CM, Valk GD, de Sonnaville JJ et al (2003) Quality of care for patients with type 2 diabetes mellitus-a long-term comparison of two quality improvement programmes in the Netherlands. Diabet Med 20:846-852. doi:10.1046/j.1464-5491.2003.01009.x

13. McGlynn EA, Asch SM, Adams J et al (2003) The quality of health care delivered to adults in the United States. N Engl J Med 348:2635-2645. doi:10.1056/NEJMsa022615 
14. American Diabetes Association (2005) Clinical practice recommendations. Diabet Care 28(Suppl. 1):S1-S79

15. Commendatore V, Dieuzeide G, Faingold C, DIFAR Academic Committee et al (2013) Registry of people with diabetes in three Latin American countries: a suitable approach to evaluate the quality of health care provided to people with type 2 diabetes. Int J Clin Pract 67(12):1261-1266. doi:10.1111/ijcp.12208

16. Larme AC, Pugh JA (1998) Attitudes of primary care providers toward diabetes: barriers to guideline implementation. Diabet Care 21:1391-1396. doi:10.2337/diacare.21.9.1391

17. Anderson RM, Fitzgerald JT, Funnell MM, Gruppen LD (1998) The third version of the Diabetes Attitude Scale. Diabet Care 21:1403-1407. doi:10.2337/diacare.21.9.1403

18. Grant RW, Buse JB, Meigs JB, University HealthSystem Consortium (UHC) Diabetes Benchmarking Project Team (2005) Quality of diabetes care in U.S. academic medical centers: low rates of medical regimen change. Diabet Care 28:337-442. doi:10.2337/diacare.28.2.337

19. Weingarten SR, Henning JM, Badamgarav E et al (2002) Intervention used in disease management programmes for patients with chronic illness-Which ones work? Meta-analysis of published reports. BMJ 325:925. doi:10.1136/bmj.325.7370.925

20. Prestes M, Gayarre MA, Elgart JF, Gonzalez L, Rucci E, Gagliardino JJ, DIAPREM (DIAbetes Primary Care, Registry, Education and Management) (2017) Multistrategic approach to improve quality of care of people with diabetes at the primary care level: study design and baseline data. Prim Care Diabet 11(2):193-200. doi:10.1016/j.pcd.2016.12.002

21. Ferrante D, Linetzky B, Konfino J, King A, Virgolini M, Laspiur S (2011) Encuesta Nacional de Factores de Riesgo 2009: evolución de la epidemia de enfermedades crónicas no transmisibles en Argentina Estudio de corte transversal. Rev Argent Salud Pública 2(6):34-41

22. Sociedad Argentina de Diabetes (1998) Programa de Capacitación Diabetológica para Médicos Generalistas (PROCAMEG). Rev Soc Argent Diabet 32:205-210

23. Blonde L, Aschner P, Bailey C, Ji L, Leiter LA, Matthaei S, Global Partnership for Effective Diabetes Management (2017) Gaps and barriers in the control of blood glucose in people with type 2 diabetes. Diabet Vasc Dis Res 14(3):172-183

24. Owens DR, Monnier L, Barnett AH (2017) Future challenges and therapeutic opportunities in type 2 diabetes: changing the paradigm of current therapy. Diabet Obes Metab (Epub ahead of print)
25. Lu S, Harris MF (2013) Prevention of diabetes and heart diseasepatient perceptions on risk, risk assessment and the role of their GP in preventive care. Aust Fam Physician 42:328-331

26. Posadzki P, Mastellos N, Ryan R et al (2016) Automated telephone communication systems for preventive healthcare and management of long-term conditions. Cochrane Database Syst Rev 12:CD009921. doi:10.1002/14651858.CD009921.pub2

27. Vachon B, Désorcy B, Gaboury I et al (2015) Combining administrative data feedback, reflection and action planning to engage primary care professionals in quality improvement: qualitative assessment of short term program outcomes. BMC Health Serv Res 18(15):391. doi:10.1186/s12913-015-1056-0

28. Seidu S, Walker NS, Bodicoat DH, Davies MJ, Khunti K (2016) A systematic review of interventions targeting primary care or community based professionals on cardio-metabolic risk factor control in people with diabetes. Diabet Res Clin Pract 113:1-13. doi:10.1016/j.diabres.2016.01.022

29. Health Quality Ontario (2013) Specialized nursing practice for chronic disease management in the primary care setting: an evidence-based analysis. Ont Health Technol Assess Ser 13:1-66

30. Gagliardino JJ, Lapertosa S, Pfirter G, PRODIACOR et al (2013) Clinical, metabolic and psychological outcomes and treatment costs of a prospective randomized trial based on different educational strategies to improve diabetes care (PRODIACOR). Diabet Med 30(9):1102-1111. doi:10.1111/dme.12230 Epub 2013 Jun 7

31. Gagliardino JJ, Arrechea V, Assad D et al (2013) Type 2 diabetes patients educated by other patients perform at least as well as patients trained by professionals. Diabet Metab Res Rev 29(2):152-160. doi:10.1002/dmrr.2368

32. Motta LA, Shephard MD, Brink J, Lawson S, Rheeder P (2017) Point-of-care testing clinic in South Africa. Prim Care Diabet 11:248-253. doi:10.1016/j.pcd.2016.09.008 Epub ahead of print

33. Spaeth BA, Shephard MD, Schatz S (2014) Point-of-care testing for haemoglobin A1c in remote Australian Indigenous communities improves timeliness of diabetes care. Rural Remote Health $14: 2849$

34. Donabedian A (2005) Evaluating the quality of medical care. Milbank Q 83:691-729

35. Tricco AC, Ivers NM, Grimshaw JM et al (2012) Effectiveness of quality improvement strategies on the management of diabetes: a systematic review and meta-analysis. Lancet 379(9833):2252-2261 